\title{
Awareness of Cytomegalovirus Infection among a Population of Nigerian Kidney Transplant Recipients
}

\author{
Nnamdi Chuks Menakaya \\ Medicine and Occupational Health Clinic, 11 PLC, Lagos, Nigeria \\ Email: ncmenakaya@gmail.com
}

How to cite this paper: Menakaya, N.C. (2021) Awareness of Cytomegalovirus Infection among a Population of Nigerian Kidney Transplant Recipients. Open Journal of Nephrology, 11, 304-320.

https://doi.org/10.4236/ojneph.2021.113025

Received: May 28, 2021

Accepted: July 10, 2021

Published: July 13, 2021

Copyright $\odot 2021$ by author(s) and Scientific Research Publishing Inc. This work is licensed under the Creative Commons Attribution International License (CC BY 4.0).

http://creativecommons.org/licenses/by/4.0/

\begin{abstract}
Background: Cytomegalovirus (CMV) is the most important infection in kidney transplant recipients and has significant impact on long term recipient and graft survival. Objective: The aim of this study is to assess the level of awareness of CMV infection among a population of kidney transplant recipients in Lagos, Nigeria. Subjects and Methods: The assessment of the level of awareness of CMV infection among kidney transplant recipients attending post-transplant follow-up clinics in Lagos, Nigeria was done by means of a structured pre-tested self-administered questionnaire from October 2004 to July 2005. Results: A total of 40 kidney transplant recipients were studied. Thirty-two recipients were males and eight were females with M:F ratio of $4: 1$. The mean age of the recipients was $39 \pm 11.6$ years old. The recipients' post-transplant duration ranged from 2 to 80 months (Mean $17.6 \pm 18.6$ months). Only four (10\%) of kidney transplant recipients studied had ever heard of CMV infection and only one recipient (2.5\%) was aware that CMV infection could affect a transplanted kidney, and that CMV infection could be transmitted from the donor kidney graft to the recipient. One recipient (2.5\%) was aware that blood transfusion could be a mode of transmission of CMV infection. None of the recipients was aware that CMV infection could be sexually transmitted. All the four recipients who were aware of CMV infection obtained the information from their doctors. Conclusion: Despite its significant impact on kidney transplant recipient and graft survival, the level of awareness of CMV infection and its relevance to kidney transplantation was very low among kidney transplant recipients. Transplant units in the study environment should include information and education about CMV infection and its impact on the transplant recipient and graft survival in their counseling programme for transplant recipients.
\end{abstract}




\section{Keywords}

Cytomegalovirus Infection, Awareness, Kidney Transplant Recipients

\section{Introduction}

Cytomegalovirus (CMV) is a member of family Herpesviridae and Subfamily $\beta$ Herpesviridae and measures between 150 nanometres $(\mathrm{nm})$ and $200 \mathrm{~nm}$ in diameter. It has a lipid bilayer envelope, an icosahedral capsid surrounded by a protein matrix and a genome or inner core composed of a $64 \mathrm{~nm}$ double stranded linear DNA molecule [1]. The CMV genome has approximately 240 kilobases and includes more than 200 genes encoding at least 33 structural proteins, some of which are glycoproteins. The viral envelope is composed of at least eight glycoproteins and most of the neutralizing antibodies are directed against glycoprotein $\mathrm{B}[\mathrm{gB}]$ and glycoprotein $\mathrm{H}[\mathrm{gH}]$. These two glycoproteins also determine the strain of CMV [1].

Following primary CMV infection in the normal host, long-term immunity develops and controls viral persistence, a situation that is lacking following solid-organ transplantation. While humoral immunity provides the best evidence of previous infection and the ability to transmit the virus, cytotoxic T lymphocytes are the main host defense against CMV [2]. Failure to reconstitute CMV-specific cellular immunity after transplantation leads to progressive CMV disease [2]. The requirements of kidney transplant recipients for immunosuppressive drugs can lead to expression of varying degrees of virulence and reactivation of latent CMV virus in the transplant recipient [3]. Rubin [4] in 1990 noted that the critical exogenous factor influencing CMV reactivation following transplantation was the type and intensity of immunosuppressive therapy.

Kidney transplantation offers the greatest potential for full return to a healthy, productive life for most patients with end-stage kidney failure and has become the preferred treatment modality for them [5]. However, it is an expensive procedure and involves a painstaking process. Since the first successful kidney transplant in Nigeria was carried out at a private medical facility in Lagos in March 2000, several other transplant centres have sprang up in different parts of the country and between them have carried out over two hundred kidney transplants [6].

Cytomegalovirus (CMV) infection is the most important infection in kidney transplant recipients [7] [8] [9]. Sagedal et al. [10] in a cohort of 471 consecutive kidney transplant recipients showed that early asymptomatic CMV infection (occurring in the first 100 days after transplantation) was an independent risk factor for recipient overall mortality. Glenn [11] also demonstrated that incidence of allograft rejection was significantly higher in kidney transplant recipients with antecedent CMV infection. Antecedent CMV infection is common among Nigerian transplant recipients as over $90 \%$ of the recipients are CMV-IgG 
seropositive at the time of transplantation [12]. Antecedent CMV is also common among Nigerians [13] [14] [15].

Although no published studies in the literature on post-transplant cytomegalovirus infection among kidney transplant recipients are available from Nigeria, studies from Tunisia, Iran, Italy and China have reported CMV infection rates ranging from $8.75 \%$ to $34.3 \%$ among post kidney transplant recipients [16] [17] [18] [19]. The wide disparity in the reported prevalence of CMV infection is a reflection of the varying methods employed for diagnosis of CMV infection such as CMV-DNA [16], serology [17] or CMV quantitative nucleic acid testing [19].

To the best of this author's knowledge, no study assessing kidney transplants' awareness of CMV infection has been reported in literature. However, there have been a few reports on the knowledge and awareness of CMV infection among obstetric study populations [20] [21]. For instance, Ogbonna and Umeora [20] in a study of seroprevalence of cytomegalovirus antibodies among 204 women attending antenatal clinic at a tertiary healthcare facility in Abakaliki, southeast Nigeria observed that 201 (98.5\%) of them were not aware of CMV infection. Jiveon et al. [21] in a survey of 643 women from seven different geographic locations in the United States observed that only 142 (22\%) of the women had heard of CMV infection. Furthermore, among the women who had heard, a healthcare provider was the most likely source of the information. However, most of the women could not correctly identify the modes of transmission of CMV infection or its prevention [21]. Cytomegalovirus infection in pregnancy is associated with congenital abnormalities [20] [21].

This study aimed to assess the level of awareness of CMV infection among a population of kidney transplant recipients in Nigeria. Originally a small part of a study designed to assess the risk factors associated with CMV infection among transplant recipients in the study environment (Appendix 1), this paper assumed more relevance on account of the findings from the study in the context of a growing kidney transplant population in the study environment. The importance of the study essentially lies in the significant impact of CMV infection on long term kidney transplant recipients and graft survival [10], which makes it important for potential kidney transplant recipients to be aware of the infection, its modes of transmission as well as its preventive measures.

\section{Materials and Methods}

The assessment of the level of awareness of CMV infection among the kidney transplant recipients was carried out between October 2004 and July 2005 using a structured pre-tested self-administered questionnaire which evaluated awareness of CMV infection as part of a study that assessed the risk factors for CMV infection in the study population (Appendix 1 Section G). As there were no previous studies in literature relating to the study objective, the questionnaire was designed by the author from a review of literature relating to CMV infection and risk factors for CMV infection in kidney transplant recipients [10] [22]-[27]. 
The questionnaire was in English language which is Nigeria's lingua franca and was pretested in a pilot study involving 33 kidney transplant recipients.

It sought information about whether the study subjects had ever heard of CMV infection and the source of the information. It also enquired about the subjects' awareness of the impact of CMV infection on kidney transplant and the modes of transmission of CMV infection.

The study subjects were recruited from kidney transplant recipients attending post-transplant follow-up clinics at three centres in Lagos, Nigeria namely; the Lagos University Teaching Hospital (LUTH) Lagos, St. Nicholas Hospital (SNH) Lagos and Life Support Medical Centre (LSMC) Ikeja.

\section{Sample Size Determination}

The equation used to calculate minimum sample size in the study was [28]:

$$
n=Z^{2} P q / d^{2}
$$

where:

$$
n=\text { minimum sample size }
$$

$Z=$ normal standard deviation (Which corresponds to the desired confidence for the study at a $95 \%$ confidence interval) $[Z=1.96]$

$P=$ Prevalence

$q=1-$ Prevalence

$d=$ Precision set at 0.05

The sample size was determined from $80 \%$ prevalence rate in the following equation:

$$
n=\left(1.96^{2} \times 0.8 \times 0.2\right) / 0.05^{2}=246
$$

However, using the equation [28]:

$$
n f=n /\{1+(n / N)\}
$$

where:

$n f=$ the desired sample size when the entire study population size is less than 10,000

$N=$ the estimate of the study population size which was 85 kidney transplant recipients in the study area

$$
n f=246 /\{1+(246 / 85)\}=63
$$

The sample size was thus determined as 63. However, a pilot study of the three centres hosting post-transplant follow-up clinics in Lagos showed the following number of recipients being followed up at the respective centres during the period of study:

St Nicholas Hospital, Lagos-40

Lagos University Teaching Hospital, Idi-Araba-5

Life Support Medical Centre, Ikeja-7

One (1) recipient was reporting to all three centres. This gave a total of 53 transplant recipients being followed up in the study environment at the time of the study. Of this number, 40 consented to and participated in the study. The 
break down from the centres was as follows:

St. Nicholas Hospital, Lagos-33

Lagos University Teaching Hospital, Idi-Araba-4

Life Support Medical Centre, Ikeja-2

An additional one (1) kidney transplant recipient who participated in the study was reporting to all three centers making a total of 40 kidney transplant recipients who participated in this study. Information on immunosuppressive drug regimens of the study participants were obtained from the self-administered questionnaire (Appendix 1 Section G) and individual study participants' case records.

The Microsoft Excel and EPI-Info 2002 statistical software were used for data entry and analysis. Frequency distributions were generated for nominal and ordinal variables while measures of central tendency i.e. mean plus standard deviation were computed for quantitative variables.

\section{Results}

Study participants' characteristics are illustrated in Figure 1 and Figure 2. A total of 40 kidney transplant recipients participated in the study. Thirty-two recipients $(80 \%)$ were males and eight $(20 \%)$ were females giving a male to female ratio of 4:1 (Figure 1). The mean age of the recipients was $39 \pm 11.6$ years (range 17 - 57 years) (Figure 2). The post-transplant duration in the recipients studied ranged from 2 to 80 months (Mean $17.6 \pm 18.6$ months). Thirty-one recipients $(77.5 \%)$ had received their kidney transplant more than four months before the study while nine $(22.5 \%)$ had their transplants two to four months before the study.

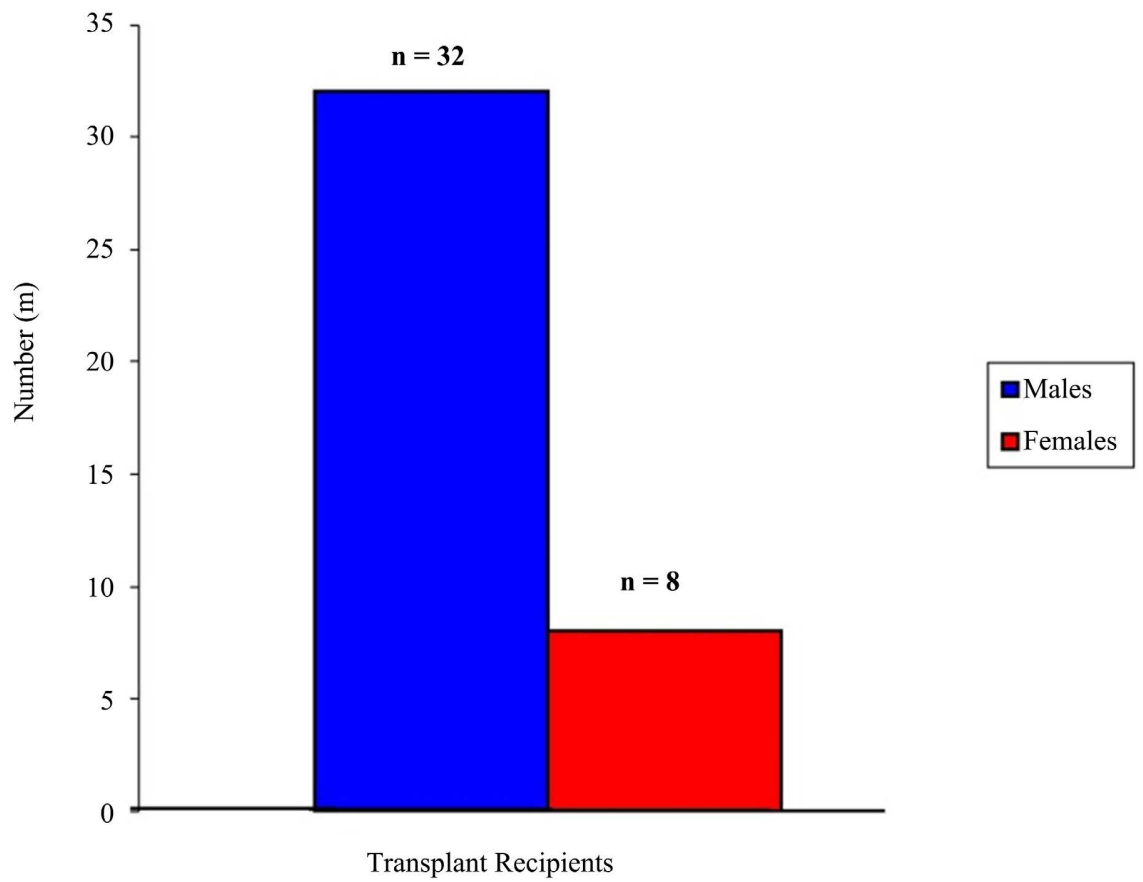

Figure 1. Number and gender distribution of kidney transplant recipients. 


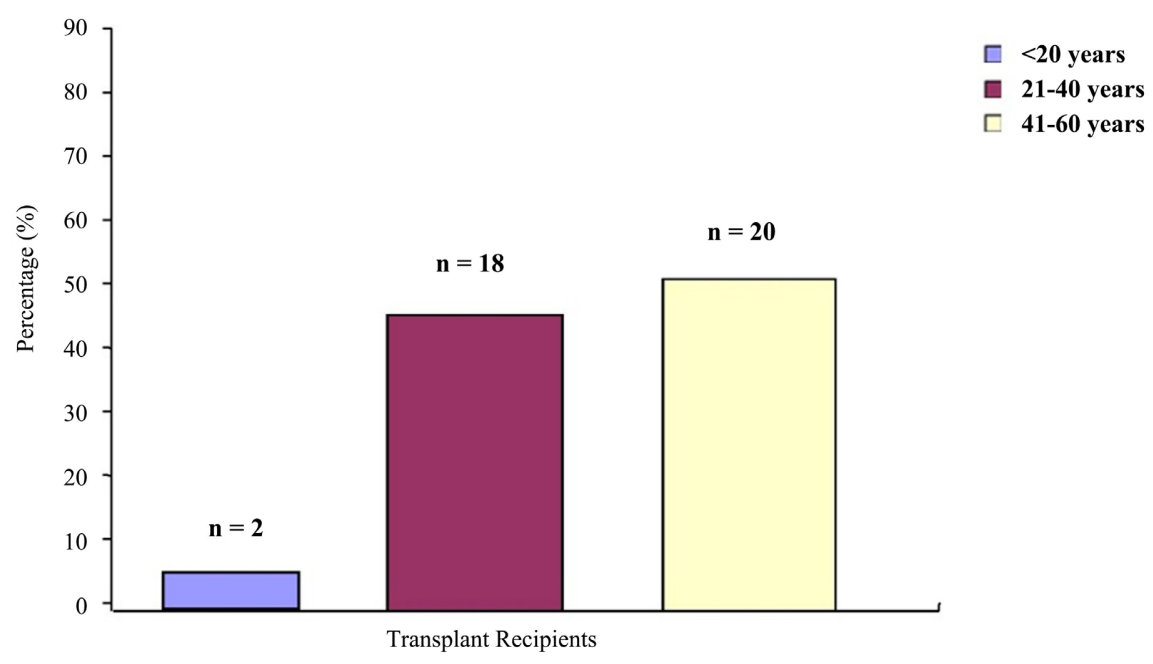

Figure 2. Age distribution of kidney transplant recipients (percent proportion).

\section{Awareness of Cytomegalovirus infection}

Pattern of study participants' awareness of CMV infection is illustrated in Table 1 . Only four $(10 \%)$ of the forty kidney transplant recipients had ever heard of CMV infection (Table 1). Also only one recipient (2.5\%) was aware that CMV infection could have an impact on kidney transplant. Furthermore, just one recipient $(2.5 \%)$ knew that infection could be transmitted to the recipient from a donor kidney graft. Again, only one recipient (2.5\%) was aware that CMV infection could be transmitted through blood transfusion. None of the transplant recipients was aware that CMV infection could be sexually transmitted. All the four recipients who were aware of CMV infection obtained the information from their doctors.

All the 40 kidney transplant recipients studied were on immunosuppressive drugs at the time of the study. Twenty-two recipients (55\%) were on cyclosporine, prednisolone and mycophenolate mofetil combination while 14 (35\%) were on cyclosporine, prednisolone and azathioprine (Table 2). Four recipients (10\%) were on other medications such as sirolimus or tacrolimus/cyclosporine/prednisolone combination. Of these four recipients, two were on prednisolone/mycophenolate mofetil/sirolimus combination, one recipient was on Prednisolone/Mycophenolate/ Tacrolimus combination while one other transplant recipient was on a two-drug combination regimen of cyclosporine and prednisolone (Table 2).

\section{Discussion}

This was a simple study but the first of its kind in Nigeria which now has a growing kidney transplant population [6] [12]. Moreover, to the best of this author's knowledge, there has been no similar study reported in literature examining the level of awareness of CMV infection among kidney transplant recipients.

This study was carried as part of a larger study on the prevalence of, and risk factors associated with cytomegalovirus infection among kidney transplant recipients in Lagos, Nigeria, for a nephrology fellowship dissertation about 16 years 
Table 1. Cytomegalovirus (CMV) awareness indices of study participants.

\begin{tabular}{ccc}
\hline CMV awareness indices & $\begin{array}{c}\text { Number of transplant } \\
\text { recipients (Yes) }\end{array}$ & $\begin{array}{c}\text { Number of transplant } \\
\text { recipients (No) }\end{array}$ \\
\hline Have ever heard of CMV infection & $4(10 \%)$ & $36(90 \%)$ \\
$\begin{array}{c}\text { Aware that CMV infection } \\
\text { can impact kidney transplant }\end{array}$ & $1(2.5 \%)$ & $39(97.5 \%)$ \\
$\begin{array}{c}\text { Aware that donor kidney } \\
\text { can transmit CMV infection } \\
\text { Aware of one other mode } \\
\text { of CMV transmission }\end{array}$ & $1(2.5 \%)$ & $38(95 \%)$ \\
\hline
\end{tabular}

Table 2. Study participants immunosuppressive drug regimen.

\begin{tabular}{cc}
\hline Immunosuppressive Regimen & Number of Recipients (\%) \\
\hline CPA & $14(35 \%)$ \\
CPM & $22(55 \%)$ \\
Others* & $4(10 \%)$ \\
\hline
\end{tabular}

CPA-Cyclosporine/Prednisolone/Azathioprine; CPM-Cyclosporine/Prednisolone/Mycophenolate mofetil. ${ }^{*}$ Prednisolone/Mycophenolate mofetil/Sirolimus-2 recipients; ${ }^{*}$ Prednisolone/Mycophenolate/Tacrolimus-1 recipient; ${ }^{\star}$ Cyclosporine/Prednisolone -1 recipient.

ago [29]. The observed dismal level of awareness about CMV infection among transplant recipients in the study and the growing kidney transplant population in the study environment has necessitated a focus on the subject and the need to draw the attention of transplant units in the study environment to the relevant study findings. At the time of this study, only one centre in Lagos, southwest Nigeria was carrying out kidney transplants in Nigeria. Several other centres from different parts of the country including the southeast and northwest regions subsequently started kidney transplant procedures [6] [12].

Kidney transplantation is an expensive and painstaking process. The importance of this study lies in the fact that kidney transplant recipients are a population with a high risk of exposure to CMV infection with the attendant potential for serious implications for both recipient and graft survival. It is therefore important that potential transplant recipients are aware of cytomegalovirus infection and its modes of transmission.

The study participants' in this study comprised of 40 kidney transplant recipients attending three post kidney transplant follow up care centres in Lagos. The number consisted of all those who consented to participate in the study out of a total of 53 transplant recipients in the study environment. As at the time of this study, kidney transplantation was relatively new in the study environment and only a few patients with end-stage kidney disease had benefited from the procedure. Moreover, by 2010 only a total of 143 kidney transplants all of which involved living donor kidney grafts had been carried out by the existing five transplant centres in Nigeria [12].

The characteristics of transplant recipients in this study were similar to those 
of kidney transplant recipients reported from other Nigerian studies [6] [12]. Majority of the transplant recipients in this study were males with male:female (M:F) ratio of 4:1. This was similar to the observation in a study by Okafor [6] who reported a male: female ratio of 4:1 from a single centre experience in Enugu, southeast Nigeria. It was also similar to the male: female ratio of 3:1 reported by Arogundade in his study of the experience of kidney transplantation in several centres in Nigeria [12]. These observations reflect the observed preponderance of males with chronic kidney disease and end-stage kidney disease in Nigeria [30] [31] [32] [33].

The mean age of recipients in this study was $39 \pm 11.6$ years. This was relatively similar to a mean age of $45.4 \pm 13.6$ years reported by Okafor from southeast Nigeria [6] and imply a young adult population impacted by end-stage kidney disease in Nigeria. The majority of kidney transplant recipients in this study were in the age group categories of 21 - 40 and 41 - 60 years. These age groups represent the economically productive group in the community.

The level of awareness of CMV infection among the transplant recipients studied was very low. Only four (10\%) of the forty kidney transplant recipients studied had ever heard of CMV infection. A low level of awareness of CMV infection has also been reported in obstetric study populations [20] [21]. Cytomegalovirus infection in pregnancy is associated with congenital abnormalities. In this study only one recipient was aware that CMV infection was a potential problem for kidney transplant recipients. Also, just one recipient was aware that CMV infection could be transmitted to the recipient through a donor kidney graft. Again, only one recipient was aware that blood transfusion could be a mode of transmission of CMV infection. None of them was aware that infection could be sexually transmitted. This lack of knowledge of the modes of transmission of CMV was also reported by Jiveon et al. [21] in a study of women of childbearing age.

In this study the attending physician was the source of information for those recipients who were aware of CMV infection. Moreover, the information about CMV infection provided by the attending physician was prompted by enquiries from the transplant recipients. Similarly, Jiveon et al. in a study of knowledge and awareness of congenital cytomegalovirus among women noted that a healthcare provider was the most likely source of the information about CMV infection [21].

Studies in the past demonstrated serologic evidence implicating the donor kidney graft as a transmitting vehicle for CMV infection [3] [22] [34]. Also while many reports had inferred that the importance of blood transfusion as a cause of CMV infection in renal transplant recipients was probably low [23] [24] [25], other studies showed that cytomegalovirus could be sexually transmitted and the prevalence high among patients examined at Sexually Transmitted Infection (STI) clinics [26] [27]. For instance, Chandler et al. [26] showed that the risk of primary CMV infection and seropositivity correlated strongly with indices of 
sexual activity such as the number of sexual partners and age at onset of sexual activity. They also noted that heterosexual contact was a major mode of transmission of CMV infection in young adults.

Since antecedent CMV infection is so common in the study environment [12] [13] [14] [15], and considering the significant impact of CMV infection on allograft and recipient survival [7] [8] [9] [10] [11] the low level of awareness about CMV infection among kidney transplant recipients observed in this study represents an important gap for transplant units in the study environment. Also, the finding that potential kidney transplant recipients requested for information about CMV infection from their physicians before they could get it also represents an important gap in kidney transplant protocols in the study environment. Therefore, transplant units should include information and education about CMV infection and its potential impact on the transplant recipient and graft survival in their counseling programmes for potential kidney transplant recipients.

The transplant recipients in this study were on various combinations of maintenance immunosuppressive regimens such as Cyclosporine/Prednisolone/ Azathioprine; Cyclosporine/Prednisolone/Mycophenolate mofetil; Prednisolone/Mycophenolate mofetil/Sirolimus; Prednisolone/Mycophenolate mofetil/ Tacrolimus and Cyclosporine/Prednisolone. These maintenance immunosuppression regimens were similar to the calcineurin-based triple drug regimen comprising Cyclosporine or Tacrolimus in combination with Azathioprine or Mycophenolate Mofetil (MMF) and Prednisolone used in other transplant centres in Nigeria [12].

While cyclosporine has minimal effect on reactivation of latent CMV virus, it interferes significantly with the ability of the host to control existing CMV infection [4]. Mycophenolate Mofetil (MMF) selectively suppresses the proliferation of $\mathrm{T}$ and B-lymphocytes thereby interfering with recipient's ability to mount immunity against CMV infection. Several studies have shown that while the use of MMF has dramatically reduced the incidence of rejection in kidney transplant recipients, a slight increase in CMV invasive disease has been noted in MMFtreated patients especially those given high doses compared to those receiving conventional azathioprine-containing immunosuppressive regimens [35] [36] [37] [38]. However, Sarmiento et al. [39] reported that recipients treated with cyclosporine/prednisolone/MMF based immunosuppressive regimen did not differ from cyclosporine/prednisolone/azathioprine regimen in relation to initial CMV infection episode after kidney transplantation. The findings of Sarmiento and colleagues were based on a case-control study in which study cases were CMV viraemia or tissue-biopsy proven CMV infection and controls were those without CMV infection. They studied 136 kidney transplant recipients of which 34 (25\%) developed CMV infection after at least three months of follow-up. Azathioprine was given at a dose of $2 \mathrm{mg}$ to $2.5 \mathrm{mg} / \mathrm{kg}$ per day while the MMF group received $2 \mathrm{~g}$ of the drug daily [39]. The dose of azathioprine (2 to $3 \mathrm{mg} / \mathrm{kg}$ 
per day) and the dose of MMF ( $1 \mathrm{~g}$ to $2 \mathrm{~g}$ daily) given to transplant recipients in this study were similar to the respective dose of the two immunosuppressive drugs in the study by Sarmiento et al. [39].

Other studies have shown that the use of such compounds as anti-thymocyte or anti-lymphocyte globulin and muromonab anti-CD3 (OKT3) monoclonal antibodies, either as induction therapy or for allograft rejection treatment, enhances the risk of symptomatic CMV infection, especially in CMV-seropositive individuals [40] [41] [42]. It has also been shown that the monoclonal antibodies not only diminish the capability of the host to mount immune surveillance but also facilitate reactivation of latent CMV from infected cells [40] [41] [42]. The fact that the immunosuppressive regimen a transplant recipient takes can impact on reactivation of latent CMV infection or development of CMV disease in the post-transplant period makes equipping the transplant recipient with basic information about CMV infection and its modes of transmission all the more important.

\section{Conclusion}

Despite its significant impact on kidney transplant recipients and graft survival, the level of awareness of CMV infection and its relevance to kidney transplantation was very low among kidney transplant recipients. Kidney transplantation is an expensive procedure involving a painstaking process and for a successful kidney transplant to succumb to CMV infection would be a very unfortunate experience. Therefore, transplant units in the study environment should include information and education about CMV infection and its potential impact on the transplant recipient and graft survival in their counseling programme for potential kidney transplant recipients.

\section{Strengths and Limitations}

This simple study was carried out between 2004 and 2005 at a time when kidney transplantation in Nigeria was still in its infancy. It is the first and so far the only study to examine the level of awareness of cytomegalovirus infection among kidney transplant recipients, a population with a high risk of exposure to CMV infection with the attendant potential for serious implications for both transplant recipients and graft survival.

The number of transplant recipients in this study was relatively small compared with those in other parts of the world where kidney transplantation has been established for several decades.

\section{Acknowledgements}

This author is grateful to all the participants in this study for their willingness to participate and to spare the time to do so. The author is also grateful to three post-kidney transplant follow-up centres from which the study participants were recruited. 


\section{Data Availability}

All the necessary data are included in the manuscript.

\section{Ethics Declaration}

The Research and Ethics Committee of Lagos University Teaching Hospital Lagos, The Management of Saint Nicholas Hospital Lagos, and The Management of Life Support Medical Centre Ikeja approved the study.

\section{Informed Consent}

Informed written consent was obtained from all the study participants after explaining the main purpose of the study to them.

\section{Consent for Publication}

The author gives his consent for this study to be published.

\section{Disclaimer}

This author is solely responsible for all contents of the manuscript.

\section{Conflicts of Interest}

This author declares no conflicts of interest regarding the publication of this paper.

\section{References}

[1] Naraqi, S. (1991) Cytomegalovirus. In: Belshe, R.B., Ed., Textbook of Human Virology, 2nd Edition, Mosby-Year Book, St. Louis, 889-924.

[2] Sia, I.G. and Patel, R. (2000) New Strategies for Prevention and Therapy of Cytomegalovirus Infection and Disease in Solid Organ Transplant Recipients. Clinical Microbiology Review, 13, 83-121. https://doi.org/10.1128/CMR.13.1.83

[3] Chou, S. (1986) Acquisition of Donor Strains of Cytomegalovirus by Renal Transplant Recipients. New England Journal of Medicine, 314, 1418-1423. https://doi.org/10.1056/NEJM198605293142205

[4] Rubin, R.H. (1990) Impact of Cytomegalovirus Infection on Organ Transplant Recipients. Review of Infectious Diseases, 12, S754-S766. https://doi.org/10.1093/clinids/12.Supplement 7.S754

[5] Goodman, W.G. and Danovitch G.M. (2001) Options for Patients with End-Stage Renal Disease. In: Danovitch, G., Ed., Handbook of Kidney Transplantation, 3rd Edition, Lippincott Williams and Wilkins, Philadelphia, 1-16.

[6] Okafor, U.H. (2016) Kidney Transplant in Nigeria: A Single Centre Experience. Pan African Medical Journal, 25, 112. https://doi.org/10.11604/pamj.2016.25.112.7930

[7] Fishman, J.A. and Rubin, R.H. (1998) Infection in Organ Transplant Recipients. New England Journal of Medicine, 338, 1741-1751. https://doi.org/10.1056/NEJM199806113382407

[8] Rubin, R.H. (1993) Infectious Disease Complications of Renal Transplantation. Kidney International, 44, 221. https://doi.org/10.1038/ki.1993.234 
[9] Liapis, H., Storch, G.A., Ashley Hill, D., Rueda, J. and Brennan, D.C. (2003) CMV Infection of The Renal Allograft Is Much More Common than the Pathology Indicates: A Retrospective Analysis of Qualitative and Quantitative Buffy Coat CMV-PCR, Renal Biopsy Pathology and Tissue CMV-PCR. Nephrol Dial Transplant, 18, 397-402. https://doi.org/10.1093/ndt/18.2.397

[10] Sagedal, S., Hartmann, A., Nordal, K.P., Kare, O., et al. (2004) Impact of Early Cytomegalovirus Infection and Disease on Long-Term Recipient and Kidney Graft Survival. Kidney International, 66, 329-337.

https://doi.org/10.1111/j.1523-1755.2004.00735.x

[11] Glenn J. (1981) Cytomegalovirus Infection Following Renal Transplantation. Review of Infectious Diseases, 3, 1151-1178. https://doi.org/10.1093/clinids/3.6.1151

[12] Arogundade, F.A. (2013) Kidney Transplantation in a Low-Resource Setting: Nigeria Experience. Kidney International, 3, 241-245.

https://doi.org/10.1038/kisup.2013.23

[13] Gwarzo, D.H., Gwarzo, A.K. and Ahmed, S.G. (2017) Seroprevalence of Cytomegalovirus Antibodies among Blood Donors in Aminu Kano Teaching Hospital, Kano, Nigeria. Nigerian Journal of Basic and Clinical Sciences, 14, 8-14.

https://doi.org/10.4103/njbcs.njbcs $47 \quad 16$

[14] Bawa, M.K., Mamman, A., Olayinka, A., Gidado, S., Waziri, N.E., Balogun, M.S., et al. (2019) Blood Donor Safety, Prevalence and Associated Factors for Cytomegalovirus Infection among Blood Donors in Minna-Nigeria. Pan African Medical Journal, 32, 6. https://doi.org/10.11604/pamj.supp.2019.32.1.13297

[15] Akinbami, A.A., Akanmu, A.S., Adeyemo, T.A., Wright, K.O., Dada, M.O. and Dosunmu A.O. (2009) Cytomegalovirus Antibodies among Healthy Blood Donors at Lagos University Teaching Hospital. South African Medical Journal, 99, 7-9.

[16] Syrine, T., Lilia, B.F., Mariem, B., Hiba, G., Lamia, R., Hela, J., et al. (2021) Pos-118 Cytomegalovirus Infection after Kidney Transplantation: Clinical Features and Risk Factors. Kidney International Reports, 6, S48. https://doi.org/10.1016/j.ekir.2021.03.126

[17] Khameneh, Z.R., Sepehrv, N. and Aghazadeh, T. (2013) Cytomegalovirus Infection among Iranian Kidney Graft Recipients. Transplantation Proceedings, 45, 178-181.

[18] Grimaldi, A., Barletta, A., Rascente, M., Pisani, F., laria, G., Maccarone, D., et al. (2005) Infectious Complications in The Renal Transplant Recipient. Transplantation Proceedings, 37, 2502-2503. https://doi.org/10.1016/j.transproceed.2005.06.009

[19] Feng, S., Yang, J., Wang, W., Hu, X., Liu, H., Qian, X., et al. (2016) Incidence and Risk Factors for Cytomegalovirus Infection in Patients with Kidney Transplantation: A Single-Center Experience. Transplantation Proceedings, 2, 2695-2699. https://doi.org/10.1016/j.transproceed.2016.08.015

[20] Ogbonna, N.A. and Umeora, O.U.J. (2016) Seroprevalence of Cytomegalovirus Antibodies among Antenatal Clinic Attendees in Abakaliki, Nigeria. African Journal of Medical and Health Sciences, 15, 24-29. https://doi.org/10.4103/2384-5589.183883

[21] Jiveon J., Marica, V., Stuart, P., Abigail, A., Gail, D., Karen, F., et al. (2006) Knowledge and Awareness of Congenital Cytomegalovirus among Women. Infectious Disease Obstetrics Gynaecology, 803, 1-7.

[22] Ho, M., Suwansirikul, S., Dowling, J.N., Youngblood, L.A. and Armstrong, J.A. (1975) The Transplanted Kidney as A Source of Cytomegalovirus Infection. New England Journal of Medicine, 293, 1109-1112.

https://doi.org/10.1056/NEJM197511272932201 
[23] Kane, R.C., Rousseau, W.E., Noble, G.R., Tegtmeier, G.E., Wulff, H., Herdon, H.B., Chin, T.D.Y. and Bayer, W.L. (1975) Cytomegalovirus Infection in a Volunteer Blood Donor Population. Infection and Immunity, 11, 719-723. https://doi.org/10.1128/iai.11.4.719-723.1975

[24] Diosi, P.E. and Tomescu, N. (1979) Latent Cytomegalovirus Infection in Blood Donors. British Medical Journal, 41, 600-662.

[25] Preiksaitis, J.K. and Strautman, T.M. (2002) The Risk of Transfusion Acquired Cytomegalovirus (CMV) Infection in Seronegative Solid Organ Transplant Recipients Receiving Unscreened Blood Products (1984-1996). Transfusion, 42, 396-402. https://doi.org/10.1046/j.1525-1438.2002.00069.x

[26] Chandler, S.H., Holmes, K.K., Wentworth, B.B., Gutman, L.T., Wiesner, P.J., Alexander, E.R., et al. (1985) The Epidemiology of Cytomegaloviral Infection in Women Attending a Sexually Transmitted Disease Clinic. Journal of Infectious Diseases, 152, 597-605. https://doi.org/10.1093/infdis/152.3.597

[27] Handsfield, H.H., Chandler, S.H., Caine, V.A., Meyers, J.D., Corey, L., Medeiros, E., et al. (1985) Cytomegalovirus Infection in Sex Partners: Evidence for Sexual Transmission. Journal of Infectious Diseases, 151, 344-368. https://doi.org/10.1093/infdis/151.2.344

[28] Araoye, M.O. (2004) Subjects Selection. In: Araoye, M.O., Ed., Research Methodology with Statistics for Health and Social Sciences, Nathadex Publishers, Ilorin, 115-129.

[29] Menakaya, N.C. (2006) Prevalence of Cytomegalovirus Infection among Renal Transplant Recipients and Their Donors in Lagos, Nigeria. Nephrology Fellowship Dissertation, National Postgraduate Medical College of Nigeria, Lagos, Unpublished.

[30] Oyediran, A.B.O. and Akinkugbe, O.O. (1970) Chronic Renal Failure in Nigerians. Tropical and Geographical Medicine, 22, 41-44.

[31] Akinsola, W., Odesanmi, W., Ogunniyi, J.O. and Ladipo, G.O.A. (1989) Diseases Causing Chronic Renal Failure in Nigerians. A Prospective Study of 100 Cases. African Journal Medical Sciences, 18, 131-137.

[32] Mabayoje, M.O., Bamgboye, E.L., Odutola, T.A. and Mabadeje, A.F.B. (1992) Chronic Renal Failure at the Lagos University Teaching Hospital. A 10-Year Review. Transplantation Proceedings, 24, 1851-1852.

[33] Ojogwu, L.I. (1990) The Pathological Basis of ESRD in Nigeria. Experience from Benin. West Africa Journal of Medicine, 9, 193-196.

[34] Orsi, E.V., Howard, J.L., Baturay, N., Ende, N., Ribot, S. and Eslami, H. (1978) High Incidence of Virus Isolation from Donor and Recipients Tissue Associated with Renal Transplantation. Nature, 272, 372-373. https://doi.org/10.1038/272372a0

[35] Hodge, E.E. (1996) The Role of Mycophenolate Mofetil in Clinical Renal Transplantation. World Journal Urology, 14, 249-255. https://doi.org/10.1007/BF00182076

[36] Gonwa, T.A. (1996) Mycophenolate Mofetil for Maintenance Therapy in Kidney Transplantation. Clinical Transplantation, 10, 128-130.

[37] Matthew, T.H. (1998) A Blinded Long-Term, Randomized Multicenter Study of Mycophenolate Mofetil in Cadaveric Renal Transplantation: Results at Three Years. Transplantation, 65, 1450-1454. https://doi.org/10.1097/00007890-199806150-00007

[38] Moreso, F., Seron, D., Morales, J.M., Cruzado, J.M., Gilvernet, S., Perez, J.L., et al. 
(1998) Incidence of Leukopenia and Cytomegalovirus Disease in Kidney Transplants Treated with Mycophenolate Mofetil Combined with Low Cyclosporinee and Steroid Doses. Clinical Transplantation, 12, 198-205.

[39] Sarmiento, J.M., Munn, S. R., Paya, C.V., Velosa, J.A. and Nguyen, J. (1998) Is Cytomegalovirus Infection Related to Mycophenolate Mofetil (MMF) after Kidney Transplantation? A Case-Control Study. Clinical Transplantation, 5, 371-374.

[40] Akposso, K., Rondeau, E., Haymann, J.P., Peraldi, M.N., Marlin, C. and Sraer, J.D. (1997) Long-Term Prognosis of Renal Transplantation after Preemptive Treatment of Cytomegalovirus Infection. Transplantation, 63, 984-976.

https://doi.org/10.1097/00007890-199704150-00012

[41] Boland, G.J., Hene, R.J., Ververs, C. and de Gast, G.C. (1993) Factors Influencing the Occurrence of Active Cytomegalovirus Infections after Organ Transplantation. Clinical Experimental Immunology, 94, 306-312.

https://doi.org/10.1111/j.1365-2249.1993.tb03448.x

[42] Pass, R.F., Whitley, R.J., Diethelm, A.G., Whelchel, J.D., Reynolds, D.W. and Alford, C.A. (1980) Cytomegalovirus Infection in Patients with Renal Transplants: Potentiation by Anti-Thymocyte Globulin and an Incompatible Graft. Journal of Infectious Diseases, 142, 9-17. https://doi.org/10.1093/infdis/142.1.9 


\section{Appendix 1}

\section{Questionnaire}

Assessment of Risk Factors Associated with CMV Infection in the Renal Transplant Recipient Study Population

Please provide accurate response to the following questions by ticking the appropriate boxes. The information given is strictly confidential. Thank you for your kind co-operation.
A. Biodata
[a] Name or initials
[b] Age:
[c] Sex: Male $\square$ Female
[d] Level of Education: $\square$ Primary School
Secondary School $\square$ Technical College
Polytechnic $\quad \square \quad$ College of Education
University $\quad \square \quad$ Postgraduate Degree
[e] Religion: Christian $\square$ Muslim
Traditionalist $\quad \square \quad$ Jehovah witness $\quad \square \quad$ None
[f] Ethnic Group:
[g] Marital Status:
Married $\square$ Single $\square \quad$ Widowed $\square$ Divorced
[h] Number of wives:
B. Blood Transfusion History
[i] Have you received blood transfusion before?
Yes $\square \quad$ No
[ii] If your response to [i] above is yes, state number of times
[Tick appropriate box]
[a] 1 - 5 times
[b] 5 - 10 times
[c] More than 10 times
[d] Don't know
[iii] When were you transfused for the first time?
Less than 3 months ago $\square \quad 3$ - 6 months ago
6 - 12 months ago
$\square \quad$ More than 12 months ago
Don't remember
[iv] What type of blood transfusion [s] did you receive?
[d] Whole blood
[e] Packed cells
[f] Don't know
[g] Others [specify]
[h] When last did you receive blood transfusion?
1-3 months ago $\square \quad \square$ - 6 months ago
More than 6 months ago 


\section{Sexual History}

[i] Are you sexually active Yes $\square \quad$ No

[ii] If your response to [I] above is yes, state whether

[a] Multiple partner

[b] Single partner

[iii] How long have you been sexually exposed?

[a] Less than 1 year

[b] 1 - 5 years

[c] 5 - 10 years

[d] $11-15$ years

[e] $15-20$ years

[f] More than 20 years

D. CMV Screening History

[i] Did you have CMV screening prior to your transplant?

[Tick appropriate response] Yes $\square \quad$ No

[ii] What was the result of your screening?
Negative
Positive
Don't know

[iii] If positive, which CMV antibody was present?
IgM
IgG
Don't know

[iv] Was your donor also screened for CMV infection?

Yes $\square$ No $\square$ Don't know

[v] If positive, which CMV antibody was present?

IgM $\square$ IgG $\square$ Don't know

\section{E. Haemodialysis History}

[i] Duration of haemodialysis

[a] Less than 3 months

[b] 3 - 6 months

[c] 6-12 months

[d] 1 - 2 years

[e] 3 - 5 years

[f] More than 5 years

[ii] Frequency of haemodialysis

[a] Once a week

[b] Twice a week

[c] Thrice a week

[d] Less than once per week

F. History of Immunosuppressive Drug Therapy

[i] Tick the immunosuppressive drugs you are currently on after you had your kidney transplant.
[a] Cyclosporine
[b] Prednisolone
[c] Azathioprine 
[d] OKT 3

[e] Mycophenolate-mofetil

[f] Anti-lymphocyte globulin

[g] Don't know

[ii] Date of transplant [month/year]

\section{G. Awareness of CMV Infection}

[i] Have you ever heard of cytomegalovirus infection? Yes $\square \quad$ No

[ii] How did you hear about it?

[a] Through the doctor

[b] By reading about it

[c] Through the internet

[d] Through the television medium

[e] Through the radio medium

[f] Others [specify]

[iii] Does it affect kidney transplant in any way?

[a] Yes, it does

[b] No, it does not

[c] I don't know if it does

[iv] How can somebody get CMV infection?

[a] Through mosquito bite

[b] Through blood transfusion

[c] Through sexual intercourse

[d] Through a donated kidney

[e] Through kissing

[f] I don't know 